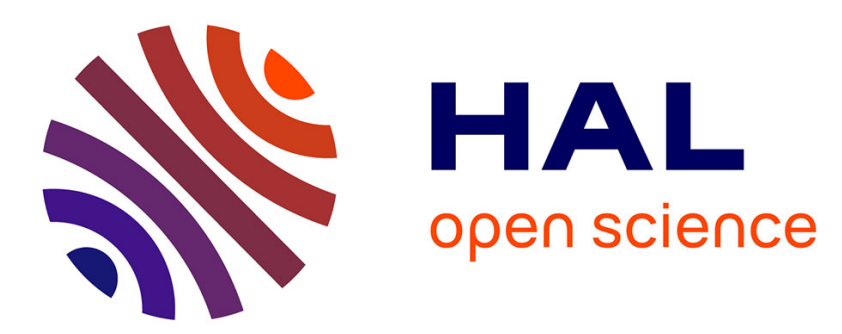

\title{
Fluoroalkylation of aryl ether perfluorocyclobutyl polymers
}

Clark Ligon, Bruno Ameduri, Bernard Boutevin, Dennis Smith

\section{To cite this version:}

Clark Ligon, Bruno Ameduri, Bernard Boutevin, Dennis Smith. Fluoroalkylation of aryl ether perfluorocyclobutyl polymers. Polymer Bulletin, 2008, 60, pp.343-349. 10.1007/s00289-007-0866-6 . hal-00267973

\section{HAL Id: hal-00267973 https://hal.science/hal-00267973}

Submitted on 31 Mar 2008

HAL is a multi-disciplinary open access archive for the deposit and dissemination of scientific research documents, whether they are published or not. The documents may come from teaching and research institutions in France or abroad, or from public or private research centers.
L'archive ouverte pluridisciplinaire HAL, est destinée au dépôt et à la diffusion de documents scientifiques de niveau recherche, publiés ou non, émanant des établissements d'enseignement et de recherche français ou étrangers, des laboratoires publics ou privés. 


\title{
Fluoroalkylation of aryl ether perfluorocyclobutyl polymers
}

\author{
S. Clark Ligon, Jr. , Bruno Amedurib, Bernard Boutevin ${ }^{\mathrm{b}}$, Dennis W. Smith, Jr. ${ }^{\text {a* }}$ \\ a Advanced Materials Research Laboratories, Department of Chemistry and Center for \\ Optical Materials Science and Engineering Technologies (COMSET), Clemson \\ University, Clemson, SC 29634, USA \\ ${ }^{\mathrm{b}}$ Laboratoire de Chimie Macromoleculaire, Ecole Nationale Superieure de Chimie de \\ Monpellier, 34053 Montpellier Cedex 1, France \\ *Corresponding author. Tel.: +1 864656 5020; fax: +1 8646566613 \\ E-mail address: dwsmith@clemson.edu
}

\begin{abstract}
Post functionalizaion of aryl ether perfluorocyclobutyl (PFCB) polymers with fluoroalkyl side chains was accomplished with Umemoto's FITS reagents. The fluoroalkylated PFCB polymers (20\% functionalized) showed increases in both hydrophobicity and oleophobicity. Static contact angle for hexadecane was increased after fluoroalkylation from $0^{\circ}$ to greater than $30^{\circ}$ for both PFCB polymers. Increased oil repellency makes these materials potential candidates for coatings applications.
\end{abstract}

Keywords: Fluoroalkylation; Fluoropolymers; Post-functionalization

\section{Introduction}

Fluoropolymers find use in a variety of high tech applications due to their generally high thermal, chemical, and oxidative stability [1-3]. More specifically, amorphous fluoropolymers are gaining interest for use as core and cladding in optical fibers since they do not appreciably absorb at telecommunication wavelengths $[4,5]$. Perfluorocyclobutyl (PFCB) polymers are a class of amorphous fluoropolymers which find use in these optical applications [6,7], in aerospace coatings applications [8], and in battery electrolyte applications $[9,10]$. Such breadth in applications stems from the ease 
in processing allowed by PFCB chemistry. PFCB polymers are formed by the thermally induced cycloaddition of aryl trifluorovinyl ethers [11]. The aryl trifluorovinyl ether monomers are stable and may be synthesized from a variety of commercially available phenols [12]. Alternatively, a variety of other aryl trifluorovinyl ether monomers have been synthesized by halogen-metal exchange of 4-(trifluorovinyloxy)bromobenzene [1315]. While this methodology has worked well for incorporating functionality into the monomer, direct post functionalization of the PFCB polymer has only recently been explored. Post functionalizing PFCB polymers with fluoroalkyl tethers [16-18] provides a relatively simple method of increasing fluorine content and provides a novel handle for tailoring polymer properties. Scheme 1 shows the polymerization and conditions for fluoroalkylation.

Perfluoroalkyl groups are incorporated into polymers in a number of ways. Commercially, fluorinated telomers are readily used in the preparation of fluorinated acrylic ester polymers [2]. These polymers are well known for their very low surface energies making them repellant to both oils and water. This makes the materials useful in a number of coatings applications within the construction and textiles industry [19] and as photoresists for IC fabrication in microelectronics [20]. The breadth and importance of these applications makes the search for new perfluoroalkyl functional polymers pertinent. Two classes of polymers which have received great attention are fluoroalkyl functional polystyrene [21] and styrene/ butadiene copolymers [22,23] and fluoroalkyl functional polythiophene [24]. With this first class of polymers, interest is in low surface energy and liquid crystalline materials, while with the polythiophenes, the fluoroalkyl tether helps segregate conductive polymer chains and improve solubility and device performance. The interesting surface properties of these materials have led us to attempt reactions of perfluorohexyl iodide with aryl trifluorovinyl ether derivatives and with perfluorocyclobutyl polymers. 


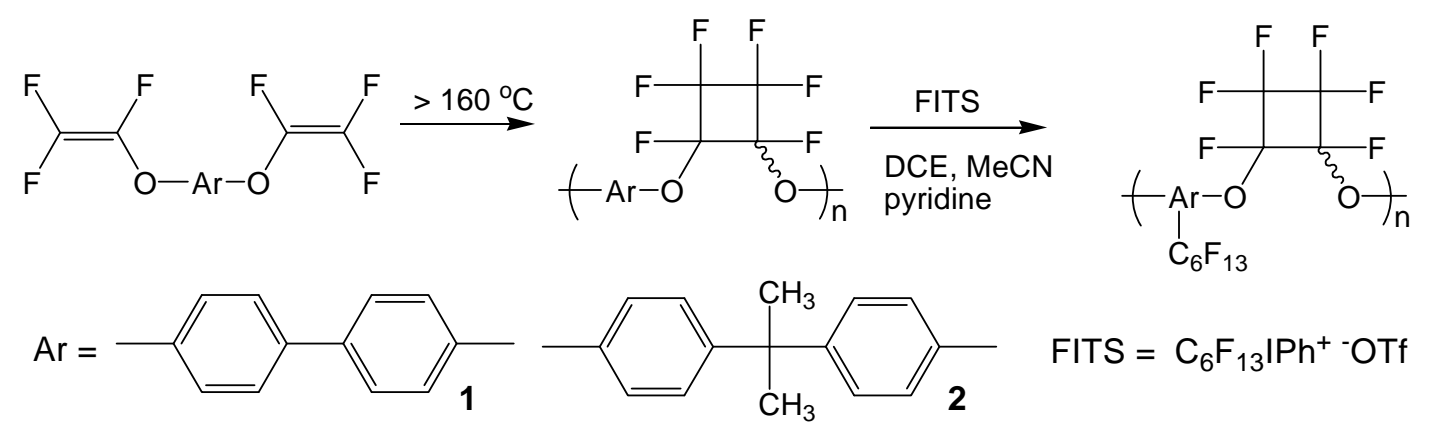

Scheme 1. Cycloaddition of aryl trifluorovinyl ethers to perfluorocyclobutyl polymers and post functionalization with fluoroalkylating agent (FITS)

\section{Experimental}

\subsection{Materials}

4,4'-bis(4-trifluovinyloxy) biphenyl (1) and 2,2-bis[4-(trifluorovinyloxy)phenyl] propane (2) were prepared as previously described[11]. These and many other aryl trifluorovinyl ethers are commercially available from Tetramer Technologies, L.L.C. and distributed by Oakwood Chemicals, Inc. of Columbia, SC. (Perfluorohexyl) Phenyliodonium Sulfonate (FITS) was synthesized from $n$-perfluorohexyliodine in two steps by previously published procedures [25].

\subsection{Instrumentation and analysis}

$300 \mathrm{MHz}{ }^{1} \mathrm{H}$ NMR and $283 \mathrm{MHz}{ }^{19} \mathrm{~F}$ NMR spectra were obtained using a JEOL ECX-300 Spectrometer. Samples were run in deuterated chloroforom using TMS as internal standard for $\mathrm{H}$ and $\mathrm{CFCl}_{3}$ for fluorine.

Gel permeation chromatography (GPC) was performed with a Waters 2695 separations module equipped with two consecutive columns (a Polymer Labs PL Gel 5 mm Mixed D and Mixed E) and a $996 \mathrm{UV} /$ vis detector. Sample concentration was 1.2 $\mathrm{mg} / \mathrm{mL}$ in HPLC grade chloroform. Retention times were calibrated using Polymer Labs EasiCal PS-2 polystyrene standards. 
Thermal gravimetric analysis (TGA) was performed on a Perkin Elmer TGA 7 using a heating rate of $20{ }^{\circ} \mathrm{C} / \mathrm{min}$ under nitrogen at a flow rate of $10 \mathrm{~mL} / \mathrm{min}$. Decomposition temperature $\left(T_{d}\right)$ is cited as the temperature of loss of $10 \mathrm{wt} \%$ of the sample. Differential scanning calorimetry (DSC) was performed with a TA Q1000 under nitrogen with a heating/ cooling rate of $10{ }^{\circ} \mathrm{C} / \mathrm{min}$. Glass transition temperatures $\left(T_{g}\right)$ are cited as the inflection point measured on the second heating scan.

Static water and oil contact angles were measured with a Rame-Hart NRL CA 100-00 115 Goniometer. Mesearuments were made on thin polymer films spin cast on to glass slides using deionized water and hexadecane as oil.

\subsection{Synthesis}

\subsubsection{Fluoroalkylation of poly1 (poly1-( $\left.\left.\boldsymbol{R}_{f}\right)\right)$}

2.0 grams of 4,4'-bistrifluorovinyloxy biphenyl (1) was heated in a roundbottom flask under nitrogen at $170{ }^{\circ} \mathrm{C}$ for two days. The product was dissolved in THF and precipitated in methanol. The dried solid was dissolved and reprecipitated two more times before drying in vacuum at $120{ }^{\circ} \mathrm{C}$ for 16 hours. The polymer poly1 $\left(M_{n} 18 \mathrm{k}\right)$ $(0.780 \mathrm{~g}, 2 \mathrm{mmol} 1 \mathrm{monomer}$ units) was dissolved with $2.5 \mathrm{~mL}$ dichloroethane in a 100 $\mathrm{mL}$ roundbottom flask. Then, $0.20 \mathrm{~g}$ pyridine, $2.0 \mathrm{~mL}$ acetonitrile, and $1.49 \mathrm{~g}$ FITS were added. The mixture was stirred at room temperature under nitrogen then heated to $82{ }^{\circ} \mathrm{C}$. Heating was maintained for 24 hours. After this, the reaction was cooled to room temperature and added to methanol to give an off-white precipitate. After precipitating, the polymer was redissolved in THF and precipitated into methanol. This was repeated and the polymer was then dried at $120{ }^{\circ} \mathrm{C}$ for 24 hours in vacuum before further characterization. ${ }^{19} \mathrm{~F}$ NMR $\left(283 \mathrm{MHz}, \mathrm{CDCl}_{3}\right) \delta-80.8$ (b, $\left.3 \mathrm{~F}\right),-103.5$ (b, $\left.1 \mathrm{~F}\right),-107.8$ (b, 1 F), -119.6 (b, 1 F), -120.8 (b, 1 F), -121.6 (b, 2 F), -122.8 (b, 2 F), -126.2 (b, 2 F), $127.5--132(\mathrm{~m}, 40 \mathrm{~F}) \mathrm{ppm}$.

\subsubsection{Fluoroalkylation of poly2 (poly2-( $\left.\boldsymbol{R}_{f}\right)$ )}


Monomer 2 was polymerized by heating to $160{ }^{\circ} \mathrm{C}$ neat under a nitrogen atmosphere for 2 days. The resultant polymer poly2 was dissolved in THF and precipitated into methanol. After repeating this partitioning procedure two more times, the polymer was dried in a vacuum oven at $120{ }^{\circ} \mathrm{C}$ for 24 hours. This resultant polymer poly2 was fluoroalkylated with FITS using the same procedure as poly1. ${ }^{19} \mathrm{~F}$ NMR (283 $\mathrm{MHz}, \mathrm{CDCl}_{3}$ ) $\delta-80.8$ (b, 3 F), -108.1 (b, 2 F), -121.2 (b, 2 F), -121.8 (b, 2 F), -122.7 (b, 2 F), -126.1 (b, 2 F), -127.5 - -132 (m, 36 F) ppm.

\section{Results \& Discussion}

\subsection{Synthesis and characterization of fluoroalkylated polymers}

Umemoto's FITS reagents provide a highly versatile method for attaching fluoroalklyl tethers to organic molecules [17]. While FITS reagents react with anionic nucleophiles with very high regioselectivity, they react with neutral aromatics by both ionic and radical pathways $[26,27]$. This leads to loss of regioselectivity and both ortho and meta substitution. This may be seen by ${ }^{19} \mathrm{~F}$ NMR of poly1-( $\left.\mathbf{R}_{\mathbf{f}}\right)$ (Figure 1) where the alkyl fluorines closest to the ring give different chemical shifts. Signals at -103 and -108 $\mathrm{ppm}$ are from the fluorines alpha to the ring and the peaks at -120 and $-121 \mathrm{ppm}$ are beta to the ring. Fluorine signals of these two isomers further from the ring $(-122,-123$, and $126 \mathrm{ppm}$ ) are not resolved since their chemical shifts are too close. It is predicted based on inductive effects that the peak at $-103 \mathrm{ppm}$ is from the alpha fluorines ortho to the perfluorocyclobutyl oxy group indicating that ortho substitution is more favorable (65:35). This would be expected if the perfluorocyclobutyl oxy group is ring deactivating inductively and acts as a weak ortho/ para director by pi donation. 


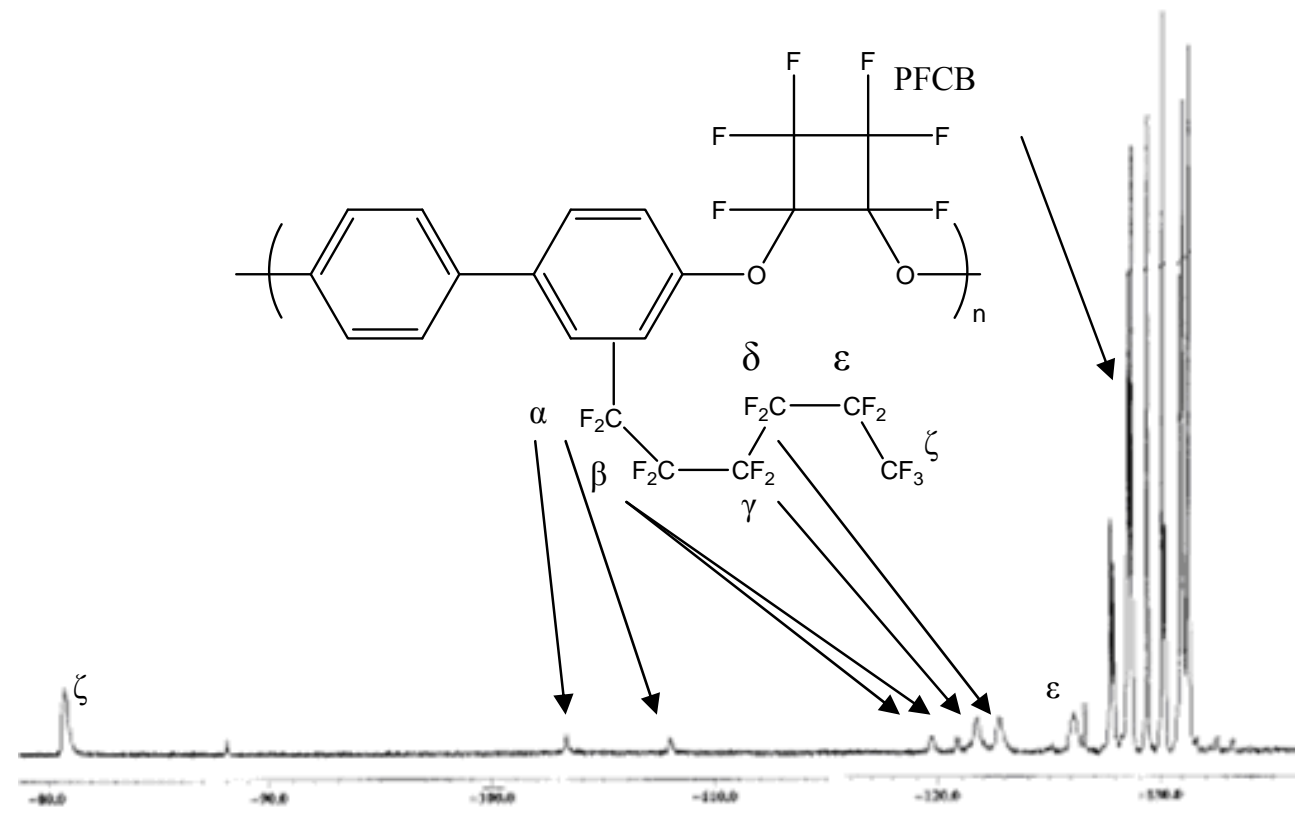

Figure $1{ }^{19} \mathrm{~F}$ NMR of fluoroalkylated poly1 (poly-($\left.\left(\mathbf{R}_{\mathbf{f}}\right)\right)$

FITS reagent was also used to fluoroalkylate poly2. The ${ }^{19} \mathrm{~F}$ NMR of this product (Figure 2) shows six peaks indicating that the tether attaches exclusively to one carbon on the aromatic ring. This is likely the carbon ortho to the isopropylidene group since this group is a very strong ortho/ para director. The multiplets at $-120 \mathrm{ppm}$ and at $-134 \mathrm{ppm}$ are from the trifluorovinyl ether end groups indicating that poly2 is much lower in molecular weight than poly1. 


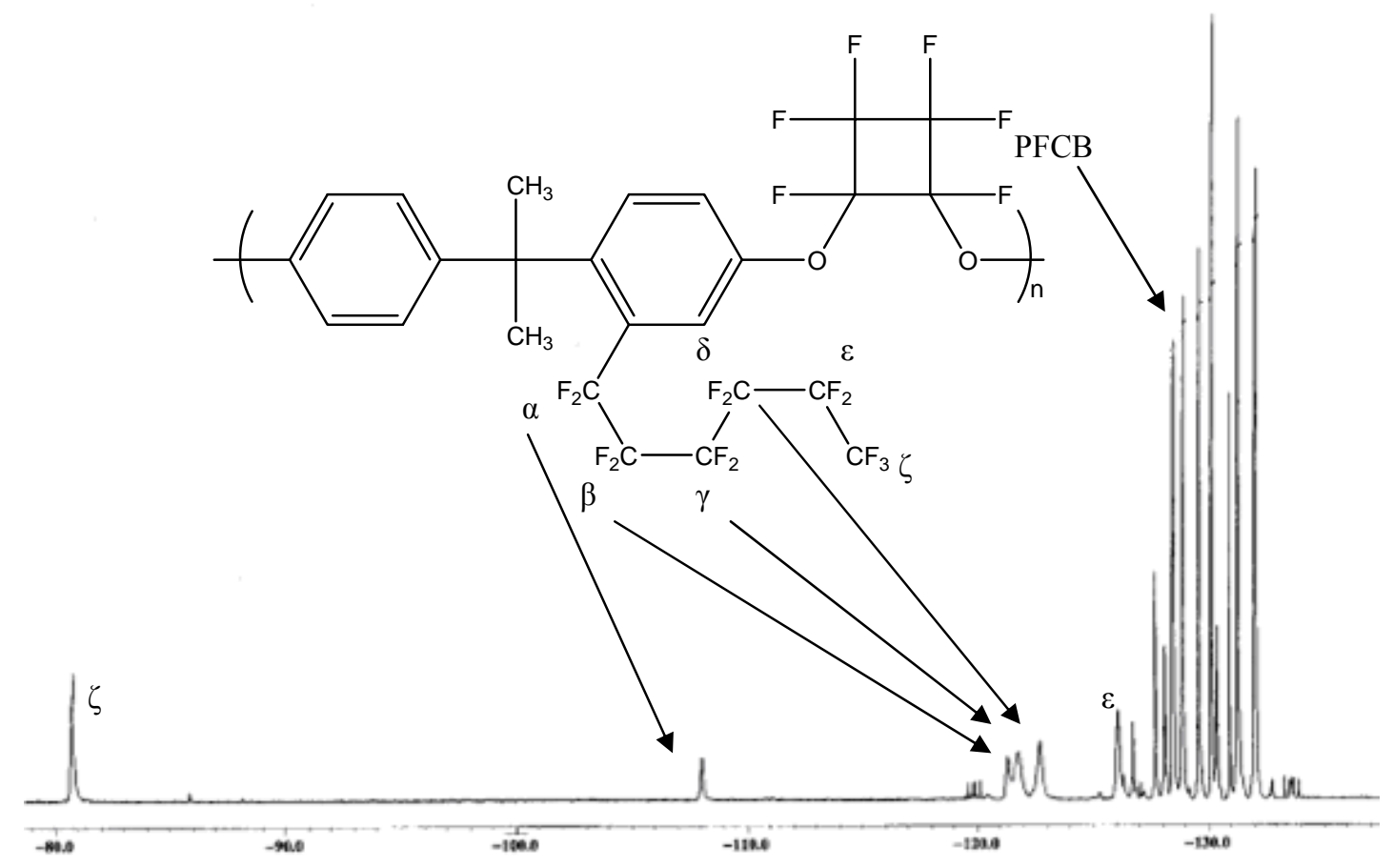

Fig. 2. ${ }^{19}$ F NMR of fluoroalkylated poly2 (poly-( $\left.\left.\mathbf{R}_{\mathbf{f}}\right)\right)$

NMR may also be used to determine extent of fluoroalkylation by peak integration of the PFCB region from $-127 \mathrm{ppm}$ to $-132 \mathrm{ppm}$ and comparing with that of the fluorinated tether. This tells that only $15 \%$ of the biphenyls of poly1 are fluoroalkylated and that $16.7 \%$ of the rings of poly2 are fluoroalkylated. Although these low yields were obtained using equal molar amounts of FITS reagent and monomer repeat, this is expected due to low reactivity of fluorinated aromatics in electrophilic substitution. Higher substitution yields may be possible by running the reaction at a slightly higher temperature for a longer time. However, one likely side reaction would be the reaction of the FITS reagent either with itself or with the iodobenzene side product to give fluoroalkylated iobobenzene.

GPC of the unfunctionalized and fluoroalkylated polymers shows a slight shift in retention time. Based on polystyrene standards, this indicates an increase in molecular weight $\left(M_{n}\right)$ from 12,300 to 14,700 for poly1 and from 6,300 to 8,500 for poly2 (Table 1). An increase in polydisperisity for the fluoroalkylated polymers is also detected. The decrease in retention time and the lack of any additional peaks indicate that the 
fluoroalkylated tether is attached to the polymer. Assuming this, degree of functionalization may then be calculated from the increase in relative molecular weight.

$\%$ functionalization $=\left[M_{n}\left(\mathbf{p o l y 1}-\left(\mathbf{R}_{\mathbf{f}}\right)\right)-M_{n}(\mathbf{p o l y 1})\right] /(\mathrm{MW}(\mathrm{Rf}) * \mathrm{DP})$

This gives a degree of functionalization of $21.2 \%$ for poly1 and a $\%$ functionalization of $42.4 \%$ for poly2. Both of these values are higher than those calculated by NMR. This indicates that the fluoroalkyl tethers may have a greater effect on the retention time of the polymers than extension of the main chain.

Table 1

Polymer properties before and after fluoroalkylation

\begin{tabular}{|c|c|c|c|c|c|c|c|c|}
\hline polymer & $M_{n}$ & $M_{w}$ & PDI & $\%$ func $^{\mathrm{a}}$ & $T_{g}\left({ }^{\circ} \mathrm{C}\right)$ & $T_{d}\left({ }^{\circ} \mathrm{C}\right)$ & $\theta\left(\mathrm{H}_{2} \mathrm{O}\right)$ & $\theta$ (oil) \\
\hline poly1 & 12,300 & 36,400 & 2.97 & 0 & 150 & 500 & 83 & wets \\
\hline poly1-( $\left.\mathbf{R}_{\mathrm{f}}\right)$ & 14,700 & 48,300 & 3.30 & 15 & 145 & 500 & 106 & 33 \\
\hline poly2 & 6,300 & 11,900 & 1.90 & 0 & 87 & 500 & 88 & wets \\
\hline poly2-( $\left(R_{f}\right)$ & 8,500 & 17,300 & 2.05 & 16.7 & 82 & 470 & 96 & 38 \\
\hline
\end{tabular}

${ }^{a}$ As determined by NMR.

Thermal properties of the functionalized and unfunctionalized polymers were also measured. While thermal stability was unchanged for poly1, the fluoroalkylated poly2$\left(\mathbf{R}_{\mathbf{f}}\right)$ has a lower $T_{d}$. This could be from formation of HF with readily available aliphatic protons beta to the aromatic ring. Differential scanning calorimetry of the polymers was also performed. A slight decrease in $T_{g}$ is measured for both of the fluoroalkylated polymers. These small changes in the glass transition would be expected for the functionalized polymers if the fluoroalkyl tethers are contributing to chain mobility. These phenomena are likely to be highly dependent on degree of functionality and on heating rate.

Hydrophobicity and oleophobicity of the polymers were also tested by measuring static contact angles with both oil (hexadecane) and water (Table 1). Hydrophobicity of poly1 and poly2 were both increased. The static contact angle of water on poly1 increased from $83^{\circ}$ to $106^{\circ}$ after fluoroalkylation. This value increased much less for 
poly2 (from $88^{\circ}$ to $96^{\circ}$ ). Oleophobicity increased dramatically after fluoroalkylation. Both of the unfunctionalized polymers were completely wetted by hexadecane. After fluoroalkylation, however, both polymers have static contact angles above $30^{\circ}$. These increases in oleophobicity indicate that these polymers may find use in new coatings applications.

\section{Conclusion}

Aryl ether PFCB polymers have been fluoroalkylated with Umemoto's FITS reagents. Degree of functionaliztion for two different PFCB polymers was between 15 and $20 \%$ molar. The low degree of functionality has a minor effect on thermal properties of the polymers. However, hydrophobicity and oleophobity are both significantly improved. The more general use of electrophilic substitutions on these aryl ether polymers is currently being explored.

\section{Acknowledgement}

The authors would like to thank NSF and CNRS for funding. Additional support was provided by DARPA. DWS, Jr. is a Cotrell Scholar of the Research Corporation.

\section{References}

[1] Ameduri B, Boutevin B. Well-architectured fluoropolymers: Synthesis, properties and applications, Amsterdam: Elsevier; 2004.

[2] Scheirs J. Modern fluoropolymers, Chichester: Wiley, 1997.

[3] Feiring AE. In: Banks RE, Smart BE, Tatlow TC, editors. Organofluorine chemistry: Principles and commercial applications, New York: Plenum Press, 1994, pp. 339.

[4] Hung MH. Macromolecules 1993; 26: 5829.

[5] Yang ZY, Feiring AE, Smart BE. J. Am. Chem. Soc. 1994; 116: 135. 
[6] Smith Jr DW, Chen S, Kumar S, Ballato J, Shah H, Topping C, Foulger S. Adv. Mater. 2002; 14 (21): 1585.

[7] Gordon J, Ballato J, Smith Jr DW, Jin J. J. Opt. Soc. Am. B 2005; 22 (18): 1654.

[8] Jin JY, Topping C, Ballato J, Foulger SH, Smith Jr DW. J. Polym. Sci.: Part A: Polym. Chem. 2004; 42: 5292.

[9] Ligon Jr SC, Topping C, Jin J, Fallis S, Irvin J, DesMarteau D, Smith Jr DW. Macromol. Chem. Phys. 2004; 205: 801.

[10] Ford L, DesMarteau D, Smith Jr DW. J. Fluorine Chem. 2005; 126 (4): 653.

[11] Babb DA, Ezzell BR, Clement KS, Richey WF, Kennedy AP. J. Polym. Sci.: Part A: Polym. Chem. 1993; 31: 3465.

[12] Babb DA, Snelgrove V, Smith Jr DW, Mudrich S. In: Hedrick J, Labadie J, editors. Step-growth polymers for high performance materials: New synthetic methods, Am. Chem. Soc. Symp. Proc. 1996; 624: 432.

[13] Ji J, Narayan-Sarathy S, Neilson RH, Oxley JD, Babb DA, Rondan NG, Smith Jr DW. Organometallics 1998; 17: 783.

[14] Rizzo J, Harris FW. Polymer 2000; 41: 5125.

[15] Spraul BK, Suresh S, Glaser S, Perahia D, Ballato J, Smith Jr DW. J. Am. Chem. Soc. 2004; 126: 12772.

[16] Balague J, Ameduri B, Boutevin B, Caporiccio G. J. Fluorine Chem. 1995; 73: 237.

[17] Umemoto T. Chem. Rev. 1996; 96: 1757.

[18] Wlassics I, Tortelli V. J. Fluorine Chem. 2006; 127: 240. 
[19] Kisa E. In: Lewin M, Sello SB, editors. Handbook of fiber science and technology: Vol II, Chemical processing of fibers and fabrics, functional finishes, Part B, New York: Marcel Dekker, 1984, (chapters 2-3).

[20] Kakuchi M, Sugawara S, Murase K. J. Electrochem. Soc. 1977; 124: 1648.

[21] Hopken J, Moeller M. Macromolecules 1992; 25: 1461.

[22] Wang J, Mao G, Ober CK, Kramer EJ. Macromolecules 1997; 30: 1906.

[23] Ren Y, Lodge TP, Hillmyer MA. Macromolecules 2001; 34: 4780.

[24] Li L, Collard DW. Macromolecules 2005; 38: 372.

[25] Umemoto T, Kuriu Y, Shuyama H, Miyano O, Nakayama SI. J. Fluorine Chem. $1982 ; 20,695$.

[26] Brace NO. J. Fluorine Chem. 1999; 96: 101.

[27] Umemoto T. In: Soloshonok VA, editor. Fluoine-containing synthons, Washington DC: American Chemical Society, 2005 (chapter 1). 